\title{
Effects of lights at the choice point on spatial alternation and position learning by normal rats and rats with bilateral lesions of the caudate nucleus'
}

HILLIAM L. MIKULAS

UNIVERSITY OF MICHIGAN

In a spatial altemation task lights at the choice point of a T-maze indicating the correct arm impaired the performance of normal rats and facilitated the performance of rats with bilaterallesions of the caudate nucleus as compared to groups without the lights. The lights had no significant effect on performance in a subsequent position learning task.

Bilateral lesions of the caudate nucleus of rats have been shown to cause a deficit in the acquisition and retention of spatial alternation (Chorover \& Gross, 1963) and a deficit in delayed response (Mikulas \& Isaacson, 1965). Possible causes of these deficits are perseveration of a pattern of responding, a deficit in short term memory, or an increase in the amount of information required to perform the task. Aspects of these hypotheses are investigated in the present study. Subjects

Thirty-three male albino rats weighing $225-250 \mathrm{gm}$ at the beginning of the experiment were divided into three groups $(\mathrm{N}, \mathrm{C}, \mathrm{O})$. Group $\mathrm{N}$ consisted of 15 normal rats; group $\mathrm{C}$ consisted of 15 rats which received bilateral radio-frequency lesions of the caudate nucleus two weeks before training; and group $O$ consisted of three rats which were subjected to the same operative procedures as group $\mathrm{C}$ except no electrode was lowered into the caudate nucleus. Verification of the lesions was made histologically following the experiment. In general the lesions involved about $10-15 \%$ of the area of the head of the caudate nucleus at a plane $1.5 \mathrm{~mm}$ anterior to bregma when the rat was in a Kreig-Johnson stereotaxic instrument.

\section{Apparatus}

The apparatus was a wooden $T$-maze painted grey with a removable screen top 6 in. above the floor. The start box, 4 in. wide and 6 in. long, was separated by a guillotine door from the $10 \mathrm{in.}$ long alley that led to the choice point. The two arms of the maze were $9 \mathrm{in}$. long and 4 in. wide. In both arms on the walls facing toward the start box, 1 in. from the end of the arm and 1 in. above the floor, was a circular window, $1-1 / 2$ in. in diameter. The guillotine doors covering the windows could be lifted to allow the rat access to a water bottle attached to the outside of the maze. At the choice point on the wall opposite the alley $4 \mathrm{in}$. above the floor and 4 in. apart were two small electric bulbs (GE82, $6.3 \mathrm{v}$, 6 candlepower). External lighting was from overhead fluorescent lights.

Procedure

Each rat was given $1 \mathrm{hr}$. of adaptation in the maze two days before the first training session. During learning of the two tasks, spatial alternation and position learning, the rats were run 20 trials a day, every other day, under $46 \mathrm{hr}$. water deprivation. A trial consisted of the rat being released from the startbox and allowed to explore the maze until it entered the "correct arm" which was the one of the two arms whose window to the water bottle was open. Following $5 \mathrm{sec}$. of drinking the rat was returned to the start box for the next trial. After the 20 trials the rat was allowed $1 \mathrm{hr}$. of free access to water in its home cage. In the spatial alternation task the correct arm was the left arm on the odd numbered trials while the correct arm was the right arm on the even numbered trials. On a given trial an error was recorded if the rat put both front feet in the incorrect arm before the correct arm. All rats were trained to a criterion of nine errorless trials out of 10 unless they did not reach criterion within 160 trials. All rats that reached criterion within 160 trials were then trained on the position learning task in which the correct arm was always on the same side, the side being random across rats. The same criterion of nine errorless trials out of 10 was used. For seven rats in groups $\mathrm{N}$ and $\mathrm{C}$ (C1-C7), the light nearest the correct arm was on during the entire trial in both tasks. For the remaining eight rats of group $\mathrm{N}$, eight rats of group $\mathrm{C}$ (C8-C15), and the three rats of group $O$, the lights were never on. Resulis

The results are shown in Table 1 . With the exception of group $\mathrm{C}$ in the "no light condition," all rats reached criterion in both tasks within 160 trials. The mean number of trials to criterion in the spatial alternation task with the light for the rats of group $\mathrm{C}$ was greater than the corresponding mean for the rats of group $\mathrm{N}$ $(t=1.67, d f=12, p<.10)$, while there was no significant difference between the corresponding means for position learning. In the spatial alternation task the mean number of trials to criterion for the rats of group $\mathrm{N}$ without the the light was significantly less than the corresponding mean for the rats of group $N$ with the light $(t=3.07$, $\mathrm{df}=13, p<.005$ ), while again there was no significant

Table 1. Mean Trials to Criterion

\begin{tabular}{llcc} 
& & Light & No Light \\
\hline \multirow{2}{*}{ Group N } & Spatial Alternation & 38.9 & 22.3 \\
& Position Learning & 21.9 & 23.0 \\
\multirow{2}{*}{ Group C } & Spatial Alternation & 67.3 & $95.7^{*}$ \\
& Position Learning & 17.6 & $25.0^{*}$ \\
\hline
\end{tabular}

* Partial data 


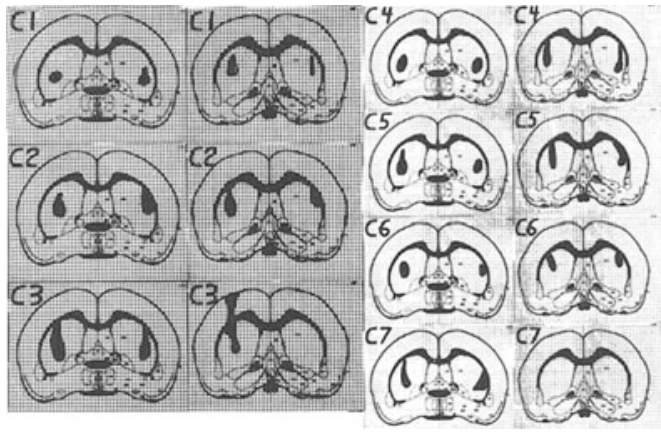

Fig. 1.

difference between the corresponding means for position learning. Of the eight rats of group $\mathrm{C}$ in the no light situation, only three (C8, C9, C10) were able to reach criterion in the spatial alternation task within 160 trials. The mean number of trials to criterion for these three in the spatial alternation was 95.7 and in the position learning was 25.0. For the three rats of group $O$ the mean number of trials to criterion in the spatial alternation was 30.0 and in the position learning was 18.3. For the rats of group $C$ there was no correlation between size of lesion and performance.

\section{Discussion}

It appears that in the spatial alternation task the presence of the lights had a slight disruptive effect on the normal rats, but a facilitative effect on the rats with lesions of the caudate nucleus. Observation of the normal rats suggests that the disruptive effect of the lights may be due to the fact that the lights are distracting. Under the "no light condition" normal rats appeared to spend less time sniffing in the area of the lamps than the normal rats in the "light condition." Two of the possible reasons for the facilitative effect of the lights on the performance of the rats with lesions of the caudate nucleus are: (1) these rats need more choice point information to learn the task; (2) the lights have a distracting effect which breaks up perseverative response tendencies.

The data on the position learning make it improbable that a deficit in short term memory could account for the effects. Also, a previous study (Mikulas \& Isaacson, 1965) suggests that although rats with lesions of the caudate nucleus may perseverate an incorrect response, they have an "expectancy" of the correct response. A simple form of perseveration such as response per-

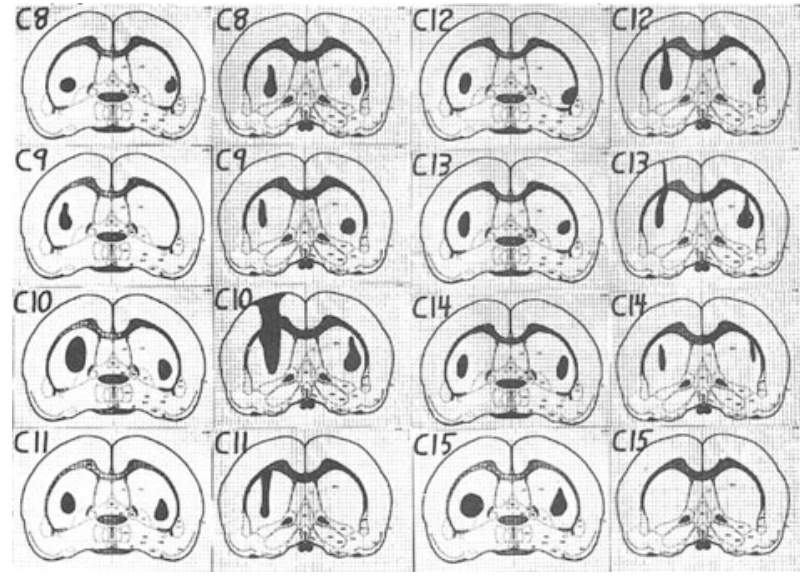

Fig. 2.

severation may be insufficient and it may be necessary to postulate perseveration of some more central mechanism as has been done with monkeys with lesions of the frontal cortex (e.g., Mishkin, 1964). Another alternative explanation is that the rats with lesions of the caudate nucleus are more easily frustrated and tend to fixate some response according to the Maier frustration-fixation syndrome (Maier, 1949). In more difficult T-maze tasks, such as some discrimination reversals, the author found that normal rats perseverated to a similar degree as rats with lesions of the caudate nucleus. In this case the behavior of the normal rats would probably be defined as fixation. Another question is whether the difference in the behavior of the caudate lesioned rats between the light and no light situations is somewhat specific to the range of lesion size used in the present experiment. Perhaps with considerably greater lesions there would be equal deficit in both conditions.

\section{References}

Chorover, S. L., \& Gross, C. G. Caudate nucleus lesions: behavioral effects in the rat. Science, 1963, 141, 826-827.

Maier, N. R. F. Frustration. New York: McGraw-Hill, 1949.

Mikulas, W. L., \& Isaacson, R. L. Impairment and perseveration in in delayed tasks due to bilateral lesions of the caudate nucleus in rats. Psychon. Sci., 1965, 3, 485-486.

Mishkin, M. Perseveration of central sets after frontal lesions in monkeys. In J. M. Warren and K. Akert (Eds.), Frontal granular cortex and behavior. New York: McGraw-Hill, 1964.

\section{Note}

1. The author and the study were supported in part by a USPHS fellowship (1-F1-MH-29, 114-01) and in part by a grant from the Surgeon General, U. S. Army (DA-MD-49-193-65-G144), to R. L. Isaacson. 